\title{
SA TRAUMA EXPERT TO HEAD WORLD BODY
}

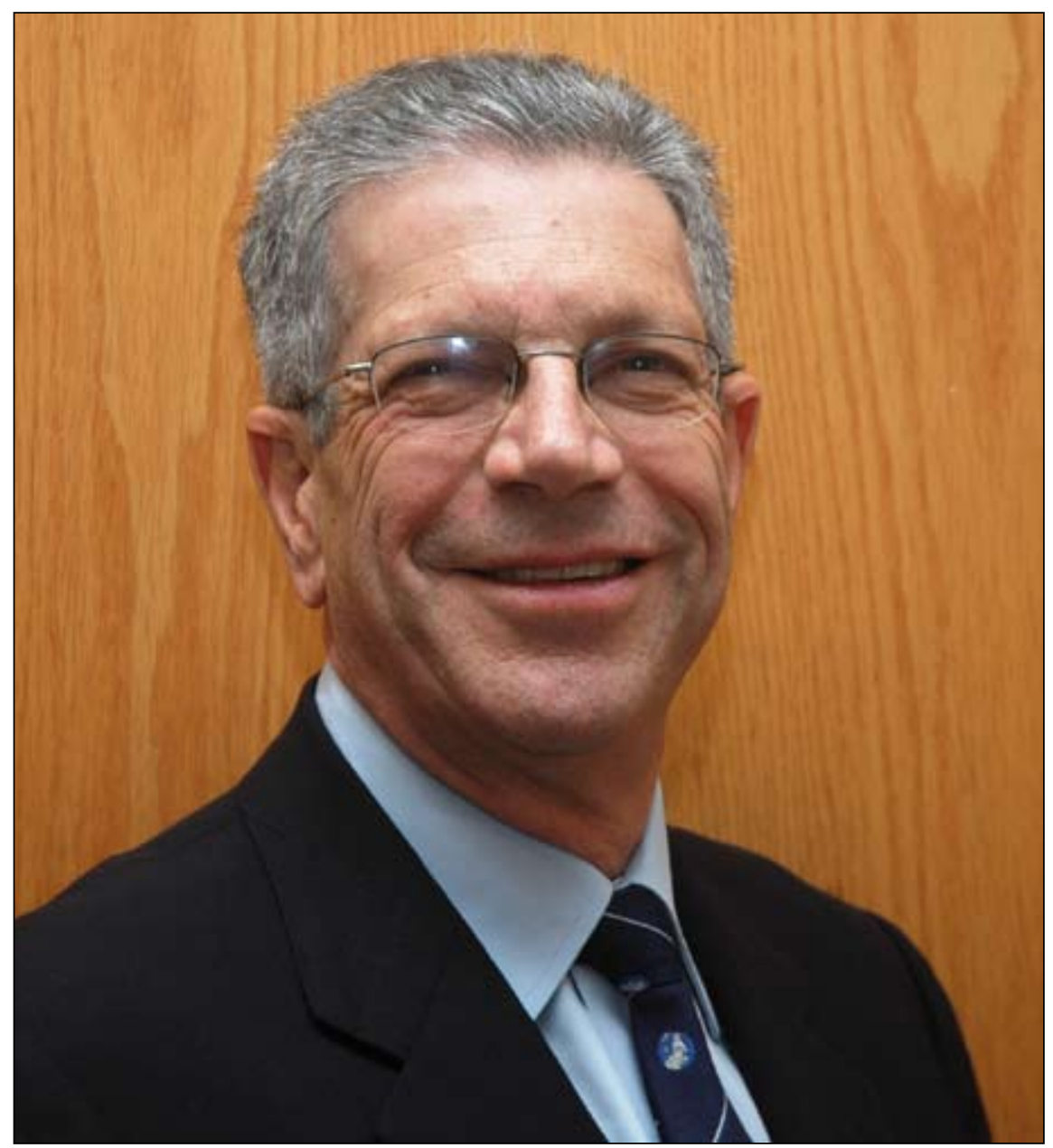

Wits University Surgery Department chief, Professor Ken Boffard, elected President of the International Society of Surgery.

In a major boost for Third World surgical training, Wits University Surgery Department chief and trauma surgery 'guru', Professor Ken Boffard, has been elected President of the International Society of Surgery.

Boffard is the first president of the society to come from Africa in its 110year existence and the first specialist trauma surgeon ever to be elected to this position. He has detailed plans to extend critically needed generalist surgical training in Third

\section{By 2007 more than 750} ATLS courses had been held in South Africa with more than 12000 doctors trained, putting the country's accident and trauma rescue services in the vanguard of advanced skills world-wide.
World countries, much of it building on educational initiatives he helped initiate.

Acknowledged as one of the world's leading authorities on trauma surgery and critical care (visiting professor at universities on five continents and member of 35 related professional associations and committees), Boffard was upbeat in outlining the goals that the new position will help him achieve.

He told Izindaba that, in surgical terms, the world had become divided into the 'rich haves (super specialists) and the poor have-nots (general surgeons)', with the former preferring to attend their specialty congresses exclusively.

The general surgeons often came from developing countries and because of limited funding, could sometimes not afford to attend his society's bi-annual congress (next one in Yokohama in 2011 with 3000 delegates expected). 'Also, some countries actively prevent citizens of other countries from attending for political reasons. Among the most successful hosts have been Mexico and South Africa (which hosted the congress in Durban in 2005).

This situation had sparked the idea of merging some of the society's existing educational initiatives with those of some of the major drug companies. Instead of putting, say R700 000, into the society's bi-annual congress, Boffard will be persuading (for example) instrument and suture manufacturing companies to invest this over five years in surgical education in the Third World.

'They already have big initiatives, but I think they'd be far more effective if they focused them through the world's biggest international surgical association,' he added, giving the example of Johnson and Johnson's R7 million surgical skills laboratory in Ghana.

In surgical terms, the world had become divided into the 'rich haves (super specialists) and the poor have-nots (general surgeons)', with the former preferring to attend their specialty congresses exclusively.

\section{Going beyond bi-annual congresses}

'So my first priority will be to broaden education beyond the congress and in particular to Third World countries, going beyond existing trauma courses like the American College of Surgeons' Advanced Trauma Life Support Course (ATLS).'

The ATLS was introduced to South Africa in 1993 after Boffard and several colleagues were chosen for training in the programme and its educational and training techniques two years earlier by the American College of Surgeons. By 
2007 more than 750 ATLS courses had been held in South Africa with more than 12000 doctors trained, putting the country's accident and trauma rescue services in the vanguard of advanced skills world-wide.

The International Society, through its trauma section, already offers the world's most advanced open trauma course, the Definitive Surgical Trauma Care (DSTC), designed mainly in South Africa, and now in 20 countries. Aimed at the doctor who doesn't usually see major trauma (i.e. more used to doing minor excisions than dealing with a mangled chest or abdomen), the course has become hugely popular world-wide.

Another of the society's courses, the National Trauma Management Course (NTMC), is designed specifically for doctors in less developed countries and began with a 'faculty of five', with all their equipment being transported to Gujarat, India in April 2000. It is now the blueprint for trauma management courses in developing countries in Asia and Africa with 6000 doctors having benefited so far.

\section{'If this campaign works it'll enhance our ability to keep our doctors and if the educational aspect works it will meet a very big need here as well as in other parts of Africa'.}

Boffard has a proven track record in developing, initiating and spreading surgical courses across the globe, the DSTC being the brainchild of his tenure as president of the International Association for Trauma Surgery and Intensive Care. So far 150 (not for profit, by invitation only) of these courses have taken place in 20 countries, training surgeons and surgical trainees in decision making, techniques to stop bleeding and definite repair of major traumatic injury.

\section{Equalising things to benefit more patients}

Boffard added however that there was 'huge scope beyond just trauma' in virtually every specialty discipline where he saw the 'haves' being able to contribute to the 'have nots'.

'So instead of only a massive biannual congress for learning (where super-specialty organisations are well catered for), you have several mini-educational courses running concurrently', he explained of his overall training battle plan.

Boffard, who has published over 52 papers in accredited medical journals and is involved in 15 ongoing research projects, is the author of Definitive Surgical Trauma Care ${ }^{1}$ and the Manual of Definitive Surgical Trauma Care $^{2}$ now in its second printing. Both are standard textbooks for surgical trauma trainees.

His second main objective during his two-year presidential tenure will be to make surgery more attractive, particularly to women, who now consist of $60 \%$ of all medical graduates but only $5 \%$ of surgeons. He said Johannesburg was leading the way in creating gender equity with half of all surgical trainees now female.

'We want show that it is possible to set up programmes aimed at making surgery more attractive to people who believe there's a lifestyle beyond surgery - surgery training doesn't have to be 100 hours a week, it can be on a part-time basis so people can raise families,' he said.

This tactic made sense for developing countries vulnerable to poaching because experience and research had shown that men were more likely to leave than women, so reducing any 'push' factor became vital.

'We also have to use the society's international credibility to develop a political lobby structure to tell poaching countries that it's no longer OK to steal doctors from Third World countries.'
'We want show that it is possible to set up programmes aimed at making surgery more attractive to people who believe there's a lifestyle beyond surgery - surgery training doesn't have to be

100 hours a week, it can

be on a part-time basis so people can raise families,' he said.

\section{Anti-poaching drive}

When Izindaba put it to Boffard that in 2008 over 100 of South Africa's registered anaesthetists were poached by an organisation known as 'Opportunities Australia', he responded that in that year his breast cancer surgery waiting list had ballooned from 'immediate' to three months. 'We've got it back to normal now thanks to goodwill from the remaining anaesthetists and extra hard work,' he added.

Boffard said there were 'definite' spin-offs for South Africa in his presidential tenure, adding: 'It's not deliberate, I've got 108 countries to look after but if this campaign works it'll enhance our ability to keep our doctors and if the educational aspect works it will meet a very big need here as well as in other parts of Africa'. He illustrated his point by saying: 'You've got just as much risk of being shot in Tzaneen as in Johannesburg, but in the former the only available surgeon may be a general surgeon or even a GP'.

Gauteng's Health and Social Development MEC, Qedani Mahlangu, who is fast making a name for herself as a hard-working, no-nonsense leader, said Boffard's election was 'proof' of the calibre of health professionals in her province.

\section{Chris Bateman}

1. Boffard, K. Definitive Surgical Trauma Care. Pratteln, Switzerland: International Association for the Surgery of Trauma and Surgical Intensive Care, 2001.

2. Boffard, K. Manual of Definitive Surgical Trauma Care. London: Hodder Arnold, 2007. 